\title{
Book Review - François Jullien, The Great Image Has No Form, or On the Nonobject through Painting: A Review
}

\section{弗兰科瓦·于连《大象无形，或从绘画论非客体》读后感}

\author{
Nadia Chaney \\ European Graduate School, Switzerland
}

\begin{abstract}
In The Great Image Has No Form, or On the Nonobject through Painting, François Jullien attempts to find a way to describe the meaning of undifferentiation in traditional Chinese painting. In every chapter, he re-examines the relationship of the painter to the arising-essence of the object and the painter's desire to go upstream from the arising in order to paint with the object as the object would come to appear in the world. He describes the tradition of Chinese literati painting as an unbroken search for the non-object and the "foundation-font" of existence. In particular, the idea of the non-object is obscured, he says, by the dichotomy of presence and absence. Rather than this dichotomy, he tells us that presence and absence are a continuum in Chinese thought, and that they indicate the arising from and returning to (which is constantly occurring) of the world to an undifferentiated fount. This book may point toward a way out of the subject-object dichotomy, by offering access to a philosophy and creative tradition that does not compartmentalize time in terms of what is gone and what does not exist, but is in a constant state of emergence and transformation, so that time is part of space, and part of matter, and is not imaginary, but is material.
\end{abstract}

Keywords: De-ontology, non-object, subject-object, emergence, phenomenology, Chinese painting

\section{摘要}

在《大象无形，或从绘画论非客体》一书中，弗兰科瓦于连意在描述中国国画中“无 分别" 的用意。在书本的章节中，作者一次次剖析画家与物体所浮现的本质间的关系以 及他想追随这种浮现至其发源处并与浮现一同来到世上的渴望。于连把中国文学界的作 画传统比作一次不间断的对非客体和存在的“基础本质”的探寻。他说，有和无之间的 对立掩盖了非客体这一观点。于连告诉我们，在中国哲学思想中，有和无并非对立，而 是一个连续体。有和无指示这个世界接连不断地从混沌中浮现而又回到混沌中去的现 象。本书向我们介绍了这样一个哲学和创作的传统，它也许能解决主体与客体间的对 立：它不把时间放在过去和不存在的束缚中，而把它看作不断发生和衍化的，使时间成 为空间、物质的一部分：它有实体，而非想象。

关键词: 道义论，非客体，主客体，出现，现象论，中国画

The Great Image Has No Form, or On the Nonobject through Painting is part of François Jullien's body of philosophical work where, based on his long study of both Chinese and Western ethics, aesthetics and systems of thought, he attempts not to compare both areas 
of study, but rather has them interact with each other by constructing an arena where they can co-exist. In The Great Image, he seeks a means by which the concept of the non-object can be examined by European thinkers whose languages tend decisively towards subject-object construction. "In reality what interests me," he writes, "is the richness of each of these philosophies, the Chinese and the Greek, that results from their respective biases, which I try to bring to light. What interests me is how they illuminate each other, each revealing the unthought of the other" (p. 39-40). Jullien is not looking to differentiate or identify Chinese thought by setting it against Western thought. Rather, he creates a venue or field wherein the character and constitution of each can emerge.

While he constructs a field of discourse between these two systems of thought on almost microscopic levels, Jullien weaves a number of guiding threads through the book. Beginning with Platonic forms, Jullien approaches the Western developmental arc of art from two angles. First, allowing that the 'pure' Platonic object is the focus of all Western art - even during and after Picasso, whom he frames as having "decomposed" the object while still being entirely focused on the object itself. Second, that the history of Western painting forms a trajectory where he suggests that each generation seeks to topple the masters of the generation before, always in service either of the object itself or of its deconstruction.

In his approach to Chinese aesthetic thought, however, Jullien takes a spiral approach. In each chapter, he re-examines the relationship between the painter and the arisingessence of the object; he also explores the painter's desire to go upstream from the arising in order to paint with the object as it comes to appear in the world. Jullien describes the tradition of Chinese literati painting as an unbroken search for the non-object and the 'foundation-font' of existence. He recognises this as a journey of spiritual maturation experienced by the painters themselves - referring to it as a kind of hygiene allowing them to travel upstream from the object. He suggests that the tradition of Chinese painting does not have a linear trajectory, but exists instead as a way of being in the world, growing and developing as a painter matures. As they reach this maturity, some painters will even take new names in order to be able to leave their time of youthful concreteness behind.

Initially, from the perspective of my Western education, I imagined Jullien would find that phenomenology was a connecting point between the two systems of thought. However, in "The Theory of the Sketch," he makes it clear that phenomenology and Taoism are not synonymous. While, for example, they both accept the incompleteness of a piece of art as legitimate, they do so for differing reasons. Referring to MerleauPonty, Jullien writes how, "The incompleteness of the sketch is justified because perception itself is never complete" (p. 65) and adds that "The phenomenology of perception takes us further back to what anchors the 'embodied' subject but does not escape the subject's perspective." (p. 66). He recognizes, however, that Laozi and the Taoist theorists of painting accept the sketch for a different reason - one that belongs to its own paradigm. Here, he comments that "...the work accomplishes more by not displaying itself, or that the work is more at work precisely when it forsakes itself and does not present itself as a "work" (p. 66). "According to that logic of immanence, we must not aspire to impose the effect, but rather act in such a way that the effect will deploy on its 
own" (p. 67). "If there is 'great completion' of what looks to be unfinished, it is because that completion is always at work, responding to various requests, open to various possibilities, having still more work to do without being hindered by 'one' particular completion that would flaunt itself" (p. 69).

Jullien does not draw us towards this exploration of Western and Chinese thought as an exercise in comparative study, but rather accepts both outlooks as possessing completely sovereign paradigmatic concerns. In particular, the idea of the non-object is obscured, he says, by the dichotomy of presence and absence. Rather than focus on this dichotomy, however, he tells us that presence and absence are a continuum in Chinese thought; they indicate a constantly occurring movement in the world - an arising from and returning to an undifferentiated fount. "If the Chinese painter paints not some particular view but an entire landscape simultaneously emerging-submerging, appearing-disappearing, he does so to shake the beholder free from the cramped enclosure of an ego-subject constituting an autonomous fate for itself vis-à-vis the consistency of objects" (p.28). "God or Ideas are absolutely invisible but essentially in existence (de deo; quod existat), whereas the tao is at the limit of the visible and 'as if' it existed" (p. 31).

To relate this distinction to my practice of arts-based community empowerment might seem far-fetched, but my reading of Jullien's inquiry into early Chinese texts on painting offer me new questions which seem highly pertinent to my own practice. What is a non-object in a group dynamic? How can a group or an individual in a group not become a Thing? How is a person or a dynamic to transform if it is already known as a representative type? From what and into what does the group form and then fade? Artsbased facilitation allows us to approach a group as a process, a chronology. In The Great Image, Jullien pushes back on the product vs. process dichotomy and offers an exploration of something he has clearly himself been deeply fascinated by.

Jullien begins by offering up his own project as a non-object. He says, "I set off in pursuit of what in principle is impossible to pursue" (p.xv). In this review, I want to take care not to create exactly what Jullien himself writes against - a didactic representational object in response to his airy, self-opening work. He acknowledges that he is "... attempting to gain access to that unobjectifiable 'fount of things,' which, once abandoned by science and philosophy, is so difficult to retrieve in the nets of the great European language" (p. xv).

While it is clearly difficult, however, it is nonetheless possible to create a work that illustrates what Jullien understands to be at the heart of Chinese literati painting: he creates a kind of non-object. The book is non-linear, to begin with; its center is its beginning. But it also possesses a quality of the ineffable; while it circles the non-object, chapter by chapter, it transforms itself, morphing the very argument it makes into a new offering.

...the emptiness of clouds and mists is not only the indistinct beyond which forms vanish at the horizon; it also permeates the interiority of forms, opens them, aerates them, liberates them, and makes them evasive. The effect of vagueness is not limited to distances rendered in perspective. That act of emptying out purifies as well the innermost part of things, releasing their capacity for aspiration (p.78). 
Some years ago I created a game for groups to play. We called it the 'Opposite Game.' This was a rhythm-poetry game using the formula, 'the opposite of $\mathrm{x}$ is $\mathrm{y}$ ' where each person in turn uses the ' $y$ ' of the person before them as their 'x.' The trick in playing this game was to introduce a word as a surprise, then players immediately threw their mind as far in any direction as they could in response to the word presented to them. The opposite of a canary could be a volcano, a miner, a penguin or even a dwarf star; the opposite of a dwarf star could be a red ant. The opposite of a red ant could be a giant sequoia. This non-specificity, the lack of a right answer, could often be disturbing at first, but it subsequently took on energy as the game progressed. This energy rose up in the centre of this circular game; there was a palpable field created by the poetry, the nonsense, and the throwing of meaning into the hands of its opposite. Jullien's reading of the Chinese literati painting tradition takes this simple idea and goes much, much further.

Jullien offers a reading of a number of Chinese Taoist texts - mostly treatises on painting - which include both the Laozi and the I Ching. His continual repetition throughout this work (whether or not he is ultimately successful in his task) is that he does not write the book to romanticize 'Chinese thought.' His aim is to find a way to bring 'de-ontology' - a moving away from Being, thing-ness, or Platonic essences - to the 'foundational.' This is a term he re-examines in every chapter. Jullien neither romanticizes nor flattens the references to cultural texts and practices, but instead relates to them with curiosity and discipline. He quotes Guo Xi:

If you accumulate an indolent breath-energy' (leading to inertia) and then you 'strain' (yourself), the brush traces will be soft and flaccid and will lack decisiveness. That flaw lies in the fact that you have not applied yourself to 'refining-distilling.' And, 'if you accumulate a muddled breath-energy' and you thereby 'blur,' the forms will be obscure and tedious; they will not be lively and will lack momentum and joy. That flaw lies in the fact that the spirit has not 'dedicated itself entirely' to that work to bring its quintessence to light (p.170).

His chapters - the artifact of the book itself - do just this. The book is hazy and undifferentiated; its core subject area (breathing) is placed perfectly in the middle of chapter eight - which lies exactly the middle of the book. In this way, the book leaves the realm of the abstract word and enters the world more in the manner of a hedge sculpture or an aquarium - not as a thing, not a hard thing, but a sensing thing; as a surprise. I hold the book in my hands and suddenly discover a little cache of glossy pages packed with images; then I find myself in chapter eight, and the complete work - which had been until now quite obscure though compelling - tumbles into place on page 109 with the words, "A long string of anecdotes serving as vignettes shows that images, as emblems, possess a power of realization that, like the images themselves, is phenomenal in nature. Partaking in the play of forces at work in the world and embodying them in their figurations, images naturally influence the course of things and events." This is compounded as I read, "formal resemblance must not be sought out as such and set forth as a goal, but must flow as a consequence from the pictorial process" (p. 112). 
As you spiral into the book, and then move back out, you become aware that you are altered - but you are unsure of exactly how that alteration has been effected. Masterfully, the overall effect is moving rather than irritating. You are emotionally related to the material - seeing it everywhere, and feeling with it too. What is it, for example, that stimulates a breath? What stimulates a line? Here, Jullien's reading of Chinese treatises and texts not only offers a profoundly attractive answer to such questions, but develops answers that are allowed to bloom over and over again.

First, Jullien deals with the notion of the indistinct. He offers the notion that Chinese paintings are working to describe in-between states - states of transition from one thing to another - like dawn, like dusk, like fog; exploring how fair weather tends towards rain. "No determination divides day and night; one emerges from within the other" (p. 4). I'm interested in this search for resemblance not representation in my creative work and in my exploration of group dynamics. What if groups could relate to each other and to the time that is passed together in this way? We would look for the blurring of categories - the transition of one thing to another - rather than to trying to pin things down or making one thing represent another. As Jullien writes “... resonance is a prolonged reverberation of an internal timbre, while resemblance is the specific reproduction of external traits. Resonance opens onto infinite vibration, while reproduction soon dries up on the surface. One deploys itself on its own as a phenomenal process, while the other remains attached to the limitation of a 'making' governed by its aim" (p. 114).

This book may point toward a way out of the subject-object dichotomy by offering access to a philosophy that doesn't compartmentalize time in terms of what's gone and what doesn't exist, but by exploring it as a constant state of emergence and transformation; time becomes part of space and part of matter and is not imaginary but material. "The globalization of thought, which began long ago, has pressed everything into the mold of European categories" (p. 58). Jullien, however, indicates the value of the unfinished, the sketch. "The uncompleted work remains alert, on the alert; but by completing it - folding it up - you make it inert" (p. 60). "Through painting, incompletion reveals the conditions - the lack and fissuring - that bring meaning into the world" (p. 65). Here, art is not separate from its meaning. It's an emergence of more matter, of more consciousness, and more relationships.

The painter is part of the landscape and is in the landscape; the extent that the painter relates to the landscape is the extent to which he can express that relationship. This is not in order to create a subject out of the landscape - for in doing such a thing, another representation is created. Another pair of opposites comes into existence. Instead this is a passage of one to the other - from self to not-self - slipping away from being to the endless breathing of becoming-and-unbecoming. "Hence, far from being conceived as a fragment of land subject to the authority of the gaze and delimited by its horizon, the Chinese landscape puts into play the functional aggregate of opposing yet corresponding elements, and it is that dynamism as a whole, whatever the scale, that the brush will be called upon to capture" (p. 122). The aim of the Chinese painter is "...not to be disconnected from nature in order to set it up in opposition to him, but, on the contrary, to reactivate through painting his primordial dependency on nature" (p. 108). 
Instead of a mimetic intention, these treatises point towards a way of painting that returns, upstream, to a source:

Paint the tree, not as an object perceived in front of you, not as its features present themselves to view, but as it 'receives its nature,' by reproducing the logic of immanence that gradually fosters its growth, from unformed to formed, until it finally brings it to completion with these particular features, as this 'so' (p. 23).

But why read this book now? I have a sense of what I might call "algorithmic terrorists" that block access to the undifferentiated fount. That makes it difficult to get to the place, not where things are unified, but where they have not yet emerged. Jullien refers to this as "upstream." If Laozi refers to the "ten thousand things" on his famous first page, then this is the era of the ten billion billion things. Where is upstream in a constant flood of images that exist only as zeroes and ones? See this short excerpt from Trevor Paglan's article "Invisible Images (Your Pictures are Looking at You)" in The New Inquiry (Dec 2016):

What's truly revolutionary about the advent of digital images is the fact that they are fundamentally machine-readable; they can only be seen by humans in special circumstances and for short periods of time. A photograph shot on a phone creates a machine-readable file that does not reflect light in such a way as to be perceptible to a human eye. A secondary application, like a software-based photo viewer paired with a liquid crystal display and backlight may create something that a human can look at, but the image only appears to human eyes temporarily before reverting back to its immaterial machine form when the phone is put away or the display is turned off. However, the image doesn't need to be turned into human-readable form in order for a machine to do something with it. This is fundamentally different than a roll of undeveloped film.

The digital world where machines interact directly with each other is an extreme example of the separation of opposites. In a world made of zeroes and ones, zero is never in the process of becoming one. There is no relationship. There is a chasm between them. The chasm is the same as the one between a living landscape and a perspectivized one - where the viewer is looking from a fixed point of perspective rather than experiencing the life of the landscape along with the painter.

So what does this book offer the current moment of hyper-representation? It is a relationship, it is a sensing state, and it is an attempt to capture the living in transition, the constantly alternating breath-energy of the world; it does so not by representing, but by breathing the wrist-brush-ink in the way that the rocks, trees and fog also breathe - to feel-see the environment and the self as its continuation, as the brush is the continuation of the wrist. "The whole play of polarities engendering forms by alternation is what produces respiration" (p. 237).

In that sense, this book is a living being - as an image on photographic paper would be if living meant to emerge from that fount. Do our digital lives enjoy the same 
respiration? Instead of the imitation of life, here is a book that offers itself up as a resonance, as a vibration stretching far back into the mists of time and place and returning as night becomes day to a time when its wisdom is needed to stretch against amongst the nets of European language.

The Western artist starts from an aesthetic; they may try to topple or deconstruct this aesthetic but there is always a starting point - creating or destroying (deconstructing) an object. What does it take to de-ontologize? Jullien asks us. Where is the non-object in the West? The deconstruction of the object is not the same as the non-object. The nonobject is not the surreal object, nor is it the process or social art-event. The non-object is that which is indistinct, inter-penetrating. It is the site of Taoist thought and cannot be reached by deconstructing Platonic thought. Jullien takes almost a refuge here in the literati paintings, where representation is not the question, but the rather the relationship and the vagueness of the interstitial zones of relationship. Jullien describes how the non-object is approached as an attempt to go upstream from the object, moving into its undifferentiated state, getting closer to what makes it what it is. When you paint a rock, therefore, you paint rock-ness - but not as essence or totality. You paint trying to have the energy of a rock - finding rock-ness - moving away from the Western tradition of trying to go for the adjectival description and delineation of rockiness. In group work we often hold an image, an identity, an objectification or description of another human being, instead of breathing with them and fully experiencing the transformations of time together.

While its implications are much deeper, I feel Jullien's offering validates both process-oriented and relational work - neither of which is recognized as valid in most educational settings. The movement of one opposite into another and the arising of opposites from within each other; the value of the in-between state where things are not set or delineated or measurable - this becomes the most salient vantage point. Instead of categorizing and hierarchizing participants and children and works of art, I am with them - seeing them emerge into the world and relating to them as far upstream as I can manage.

Even the compactness of the rock and the airiness and evanescence of the cloud are not two different materialities, only a difference in concretion. 'Clouds emanate from valleys buried deep in the mountains, and that is why rocks are called the roots of clouds.' Similarly, when you see clouds amassing around mountain peaks in the summer and assuming strange forms, 'it is because clouds are born from the rocks...' The expression 'roots of clouds' is thus not a rhetorical Figure or even a poetic image; rather, it translates the osmosis that, through the circulation of vital breath, makes all existents communicate with one another and associates them from within (p. 136).

\section{About the Author}

Nadia Chaney is a lead facilitator, trainer and process design consultant in arts-based empowerment for numerous community, activist, NGO, government, university and private-sector clients. Since 2002 she has facilitated well over two thousand events, 
workshops and trainings over four continents. She is also a professional poet, performer and visual artist. She specializes in creative-risk taking, anti-oppression and emotional intelligence. Email address: eternal.flux@gmail.com

\section{References}

Jullien, F., (2009), The Great Image Has No Form or On the Nonobject in Painting, Chicago: University of Chicago Press.

Paglen, T. (2016) Invisible Images (Your Pictures are Looking at You). The New Inquiry, 57 (Dec) p. 14-22. 